\title{
ТЕОРЕТИЧЕСКАЯ ЛИНГВИСТИКА
}

УДК $81-114.2$

DOI: $10.23951 / 1609-624 X-2018-8-51-55$

\section{АНАЛИЗ СТРУКТУРНЫХ ОСОБЕННОСТЕЙ КАТЕГОРИИ ПОСЕССИВНОСТИ}

\section{С. М. Давлетиина}

Башкирский государственный педагогический университет им. М. Акмулль,, Уфа

\begin{abstract}
Неоднородность категории посессивности обусловила существование различных точек зрения на ее структуру. Существует видение категории посессивности как бинарной оппозиции. В зависимости от семантики имени посессора, наличия в нем признаков лица, одушевленности, степени конкретности/абстрактности, а также с учетом семантики объекта обладания выделяются такие оппозиции, как отчуждамая/неотчуждаемая принадлежность, внутренняя/внешняя принадлежность, временная/постоянная посессивность, актуальное/ виртуальное обладание, юридическая/соматическая принадлежность. В рамках градуальной оппозиции посессивные отношения можно представить в виде абсолютно неотторжимых, относительно неотторжимых, окказионально неотторжимых и собственно отторжимых. Согласно другой трактовке, посессор может быть связан с объектом отношениями неотчуждаемости, полуотторжимости и отчуждаемости. Сторонники ономасиологического подхода предпринимают описание посессивности, основываясь на экстралингвистической реальности: описывают возможные типы посессесоров, возможные типы объектов обладания, прогнозируют их потенциальные отношения. Сторонники семасиологического подхода берут за основу конкретные языковые и речевые факты - посессивные конструкции.
\end{abstract}

Ключевые слова: оппозиция, неотчуждаемая посессивность, отчуждаемая принадлежность, внутреннее обладание, внешнее обладание, временная посессивность, постоянная посессивность, актуальная принадлежность, виртуальная принадлежность, ономасиологический подход, семасиологический подход.

Анализ посессивных отношений показывает, что структура этой категории весьма неоднородна. В зависимости от семантики имени посессора, наличия в нем признаков личности/неличности, одушевленности/неодушевленности, конкретности/ абстрактности, а также в зависимости от семантики имени объекта обладания, которому может быть свойственна большая или меньшая степень отторжимости, отношение посессивности может рассматриваться по-разному. Так, исследователи категории притяжательности выделяют внутри нее такие оппозиции, как отторжимая/неотторжимая посессивность (Ш. Балли, А. Фрей); внутренняя/ внешняя посессивность (Ж. Альварес, Б. Потье); временная/постоянная посессивность (В. П. Липеровский, С. Н. Цейтлин); актуальная/виртуальная принадлежность (Г. Гийом); абсолютная/относительная принадлежность (Н. А. Бутинов, Ю. М. Лихтенберг, Дж. Линч).

Неотчуждаемая (неотторжимая) принадлежность коренным образом отличается от отношений владения. Название «неотторжимая принадлежность» свидетельствует о том, что основным признаком этих конструкций, по которому они противопоставляются другим притяжательным конструкциям, считается максимально тесная, нерасторжимая связь посессора и объекта, такая, что посессор, утратив объект, перестает быть тождественным самому себе, и поэтому вне связи с объектом не мыслится.

В своей работе «Общая лингвистика и вопросы французского языка» Шарль Балли выводит два типа отношений между субъектом и объектом присущность и соотношение. «Присущность указывает, что нечто (субъект) либо принадлежит к роду, обозначаемому атрибутом, либо обладает качеством, обозначаемым этим атрибутом, свойством, которое может быть или постоянным качеством, или чем-либо случайным, состоянием или действием». «Соотношение» характеризуется автором «как отношение между двумя внешними независимыми друг от друга предметами» [1, с. 121-122].

В концепции Ш. Балли особого внимания заслуживает определение «личной сферы» логического субъекта, включающей «les choses et les êtres associés à une personne d'une façon habituelle, intime, organique (le corps et ses parties, les vêtements, la famille)》 'неодушевленные и одушевленные сущности, связанные с посессором тесной, органической связью либо привычностью взаимодействия'. Однако французский исследователь признает условность и субъективность данного понятия: «La notion de la sphère personelle est purement subjective, rien n'empêche l'imagination 
collective d'attribuer au moi des choses ayant leur existence propre, ou inversement, de détacher ce qui ne peut réellement en être séparé» ('Понятие личной сферы чисто субъективно: ничто не препятствует мысленному отнесению к обладателю объектов, имеющих отдельное от него существование, или отделению от него того, что в действительности от него неотторжимо') [2, с. 53]. Таким образом, Ш. Балли понимает под «личной сферой» субъекта не только самого человека, взятого как совокупность своих «непосредственно составляющих», но и то, что находится в его окружении и относится к нему опосредованно.

Некоторые исследователи рассматривают оппозицию отчуждаемость/неотчуждаемость как частный случай категории посессивности и характеризуют ее как скрытую категорию, в которой существенные различия не передаются грамматически. М. А. Журинская рассматривает оппозицию отторжимость/неотторжимость саму в себе вне зависимости от категории посессивности, как классическую грамматическую категорию [3, с. 252].

Французские лингвисты Г. Гийом [4] и Б. Потье [5] анализируют посессивные отношения с точки зрения их внешнего/внутреннего проявления. Внешняя посессивность соответствует ситуации, при которой объект существует независимо от субъекта. Благодаря собственной активности субъект может включать в свою личную сферу то, что имеет независимое от него существование. При внутренней посессивности объект является составной частью субъекта и не выходит за пределы последнего, поэтому со стороны субъекта не требуется никакой активности по отношению к объекту. Внешняя посессивность, по мнению исследователей, реализуется в предложениях, в которых говорится об отношениях одного лица к другому (Jacques a deux frères, il a des amis) и лица к предмету (Papa a une automobile). Следовательно, в этих случаях особую важность приобретает подкласс существительного, противопоставление антропонима неантропониму. Для внутренней посессивности это противопоставление нерелевантно, поскольку объект обладания является частью субъекта, следовательно, присущ ему внутренне.

Лингвист А. Л. Ленца упоминает заключение Ж. Альвареса о внутреннем/внешнем характере посессивности, сделанное по результатам анализа структур Il a une maison au bord de la mer (у него дом на берегу моря) и Il a honte (ему стыдно). По мнению лингвиста, различие между двумя типами отношений заключается не столько в их природе, сколько в форме их представления в языке, а именно в наличии/отсутствии детерминатива перед существительным, называющим объект обладания. Так, в первом высказывании речь идет о внешнем обладании, поскольку единица une maison обозначает предмет, имеющий независимое от субъекта $i l$ существование, и оформлена грамматически и номинативно как самостоятельная единица [6, с. 61].

Вне всякого сомнения качества и состояния внутренне присущи субъекту и поэтому неотторжимы от него. Тем не менее наличие детерминатива не всегда свидетельствует о внешнем характере посессивных отношений. Например, в высказывании Il a une grippe невозможно однозначно утверждать внешний характер обладания, основываясь лишь на том, что слово une grippe сопровождается детерминативом и оформлено как самостоятельная, не зависящая от субъекта единица. Болезни внутренне присущи субъекту, различаясь лишь временным/постоянным характером своего наличия у данного субъекта. Утверждение Л. И. Илия [7] о синтаксической природе имени может служить подтверждением отсутствия связи между детерминацией и характером обладания. Так, наличие детерминатива говорит о том, что существительное является прямым дополнением. Существительное без детерминатива не может считаться самостоятельным членом предложения, оно образует одну синтаксическую единицу с глаголом.

В рамках внешнего обладания, в тех случаях, когда обладаемое находится в отчуждаемой собственности посессора, некоторые исследователи (В. П. Липеровский [8], С. Н. Цейтлин [9]) выделяют временные и постоянные проявления обладания. В татарском языке примером временного типа отношений может служить высказывание Миндә am бар 'У меня лошадь' (возможно, она не лично моя). В качестве примера постоянного обладания можно привести высказывание Минем атым бар 'У меня есть (моя) лошадь' (она - моя). Как следует из данных примеров, в тюркских языках временный/постоянный характер посессивных отношений связан с наличием/отсутствием аффикса принадлежности при существительном, обозначающем объект обладания (ambln/am). В русском языке внешнее обладание выражается конструкцией «у X Y» У меня машина (в данный момент машина находится в моем распоряжении, но может мне не принадлежать). Постоянный характер притяжательных отношений воплощен в структуре с глаголом «быть» «у Х есть Ү» У меня есть машина (я - ее владелец, она мне принадлежит). Таким образом, в русском языке временность/постоянство посессивных отношений связаны с наличием/ отсутствием глагола «быть» в конструкции «у X (есть) $\mathrm{Y».}$

Французский лингвист Г. Гийом выдвинул оппозицию актуальная/виртуальная принадлежность. Данное противопоставление связывается с функционированием артикля и вливается в общую ги- 
йомовскую теорию актуализации языкового знака. Актуальная и виртуальная принадлежности представляют собой крайние фазы соотнесения понятия, обозначаемого существительным, с реальной действительностью и различные фазы сложного многоступенчатого процесса соотношения виртуального с действительностью. Актуальная посессивность утверждает реальную принадлежность предмета, качества, свойства конкретному, реальному лицу (la montre de l'homme 'часы мужчины', la bonté de la femme 'доброта женщины'). Виртуальная принадлежность утверждает посессивные отношения как потенциальность (la montre d'homme 'мужские часы', la bonté de femme 'женская доброта'). Последняя связана с переходом от "мысли о том, что предмет реально принадлежит субъекту мысли, что предмет может ему принадлежать» [3, с. 86]. Так, оппозиция актуальная/виртуальная принадлежность отображается при помощи детерминативов при имени посессора. В концепции Г. Гийома об актуализации языкового знака важное место занимает понятие «реальная принадлежность» или «реальное обладание» в именных сочетаниях, соединенных предлогом de. Наиболее наглядно реальное обладание проявляется в тех случаях, когда одно существительное обозначает лицо, другое - предмет: le stylo de Marc, l'appartement de Louise. Понятие peального обладания охватывает и те ситуации, когда обладателем выступает предмет, а второе существительное именует какой-либо признак, свойство предмета (la superficie du pays, le verso de la feuille). Заслугой Г. Гийома является то, что он одним из первых признал право неодушевленных существительных выступать в роли посессоров.

Перевод французской именной конструкции с предлогом de на русский язык подтверждает разницу между актуальной (реальной) и виртуальной (потенциальной) принадлежностью. Сочетания, в которых имя посессора сопровождается детерминативом, переводятся на русский язык при помощи существительного в родительном падеже: la robe de la femme - 'платье женщины', la voix de l'enfant 'голос ребенка'. Имя обладателя без детерминатива переводится при помощи соответствующего прилагательного и имеет оттенок значения «предназначенный для к.-л., свойственный к.-Л., присущий к.-л.»: la robe de femme - 'женское платье', la voix d'enfant - 'детский голос'.

Н. А. Бутинов и Ю. М. Лихтенберг делят имена объектов обладания на 2 класса, противопоставляя имена предметов, которые не могут быть отданы другому, отчуждаемым именам. В терминологии авторов эта оппозиция представлена как абсолютное/относительное обладание [10].

Не все исследователи считают, что категорию посессивности можно представить в виде бинар- ных оппозиций. Так, Дж. Линч отмечает явление, суть которого состоит в том, что объект, считающийся неотторожимым от посессора, может в определенных условиях отделяться от него (зуб, волос). Это явление лингвист называет полуотторжимостью (цит. по: [3, с. 205]).

А. В. Головачева выделяет градацию степени связанности посессора с объектом обладания: абсолютная неотчуждаемость, относительная неотчуждаемость, окказиональная неотторжимость и собственно отчуждаемость [11, с. 46-63]. В соответствии с когнитивной концепцией А. В. Головачевой в языковом сознании существует некий эталон посессора (человека, животного), обладающий неким набором обязательных для него элементов, которые характеризуются как абсолютно неотчуждаемые (голова, тело, рост, возраст, характер, душа и пр.). Относительно неотчуждаем от посессора комплекс элементов, наличие которых представляется весьма вероятным, но не обязательным для посессора (жена/муж, усы, борода, друзья). Возможные объекты обладания, объединенные с посессором общностью функций в ряде ситуаций (начальник - подчиненньии, хозяин - гость), составляют его окказиональную неотчуждаемость. Собственно отчуждаемые объекты спорадически и разрозненно выступают в качестве объектов обладания (стул, стакан, вагон).

T. А. Тулина выделяет оппозицию соматическая/юридическая принадлежность. Термин «соматическая принадлежность» подразумевает неотторжимую принадлежность и говорит не столько о принадлежности, сколько о составности (отношения «часть - целое»): la tête de l'enfant (голова ребенка), le pied de la chaise (ножка стула). Отношение юридической принадлежности «привносится извне и устанавливается всякий раз заново» (les crayons du garçon 'карандаши мальчика', le vase de ma grand-mère 'ваза моей бабушки'), в то время как «смысл соматической принадлежности составляет константу» [12, с. 48].

По мнению Дж. Лайонза, для категории посессивности релевантно противопоставление случайного необходимому. В некоторых языках обладаемое получает показатель отчуждаемости, связываясь с посессором «случайно». В том случае, если объект связан с обладателем узами необходимости, он получает показатель неотчуждаемости [13, c. 319]. Во французском языке это противопоставление прослеживается достаточно четко: «la chaîne $d u$ vélo» (цепь от велосипеда) и «la chaîne de vélo» (велосипедная цепь). В русском языке это противопоставление прослеживается, хотя и не очень последовательно: «йепь от велосипеда» (отчуждаемая и валяющаяся, скажем, в гараже, на улице, на свалке) и «велосипедная ц̧епь» (неотчуждаемая как 
деталь). Немецкий язык не передает этих различий, русским сочетаниям «велосипедная изепь» и «иель от велосипеда» соответствует одна и та же агглютинативная конструкция Fahrradkette. Следовательно, для некоторых языков оппозиция отчуждаемость/неотчуждаемость не является релевантной и поэтому не может быть выдвинута в качестве самостоятельной категории.

Различные точки зрения на выделение оппозиций внутри категории посессивности демонстрируют тяготение к двум подходам: ономасиологическому и семасиологическому. Сторонники ономасиологического подхода, основываясь на экстралингвистической действительности, стараются определить круг объектов обладания в неотторжимой и отчуждаемой собственности посессора, исходя из личной сферы каждого конкретного посессора. Сторонники семасиологического подхода рассматривают план выражения в качестве первичного фактора, оказывающего влияние на содержание.

Анализ классических и современных исследований категории посессивности не выявил кардинальных перемен в трактовке структурных отношений внутри категории: большинство исследователей рассматривают посессивность как бинарную оппозицию «отторжимость/неотторжимость». Оппозиция неотчуждаемая/отчуждаемая принадлежность получает в трактовке исследователей различные обозначения: внутренняя/внешняя посессивность, временная/постоянная принадлежность, актуальное/виртуальное обладание, соматическая/ юридическая притяжательность.

\section{Список литературы}

1. Балли Ш. Общая лингвистика и вопросы французского языка / пер. с 3-го фр. изд. Е. В. и Т. В. Вентцель; ред., вступ. ст. и примеч. Р. А. Будагова. 2-е изд., стер. М.: Эдиториал УРСС, 2001. 416 с.

2. Bally Ch. L'expression des idées de sphère personnelle et de solidarité dans les langues indo-européennes // Festschrift Louis Gauchat. Paris, 1926.

3. Журинская М. А. Именные посессивные конструкции и проблема неотторжимой принадлежности // Категории бытия и обладания в языке. М.: Наука, 1977. С. 194-258.

4. Guillaume G. Le problème de l'article et sa solution dans la langue française. Paris: Hachette et c-ie, 1919. $318 \mathrm{p}$.

5. Pottier B. Théorie et analyse en linguistique. Paris: Hachette, 1987. 224p.

6. Ленца А. Л. Широкозначность глагола и контекст. Кишинев: Штиинца, 1987. 98 с.

7. Илия Л. И. Очерки по грамматике современного французского языка. М.: Высшая школа, 1970. 176 с.

8. Липеровский В. П. Посессивные конструкции в индоарийских языках (хинди, урду, панджаби, бенгальский). М.: Институт востоковедения PAH, 2002. $163 \mathrm{c}$.

9. Цейтлин С. Н. Семантическая категория посессивности в русском языке и ее освоение ребенком // Семантические категории в детской речи. СПб.: Нестор-История, 2007. С. 201-219.

10. Бутинов Н. А., Лихтенберг Ю. М. Языки народов Меланезии // Народы Австралии и Океании / под ред. С. А. Токарева, С. П. Толстова. М.: Изд-во Академии наук СССР, 1956. С. 375-392.

11. Головачёва А. В. Категория посессивности в плане содержания // Категория посессивности в славянских и балканских языках. М.: Наука, 1989. С. 44-111.

12. Тулина Т. А. Функциональная типология словосочетаний. Киев: Вища школа, 1976. 176 с.

13. Лайонз Д. Введение в теоретическую лингвистику. M.: URSS, 2010.541 c.

Давлетшина Светлана Мансафовна, кандидат филологических наук, доцент, Башкирский государственный педагогический университет им. М. Акмуллы (ул. Октябрьской революции, За, Уфа, Республика Башкортостан, Россия, 450000).E-mail: davletshinasm@mail.ru

Материал поступил в редакциию 31.08.2018.

DOI: 10.23951/1609-624X-2018-8-51-55

\section{STRUCTURAL PECULIARITIES ANALYSIS OF THE CATEGORY OF POSSESSIVENESS}

\section{S. M. Davletshina}

Bashkir State Pedagogical University, Ufa, Russian Federation

The heterogeneity of the category of possessiveness conditioned the emergence of different points of view on its structure. There is a vision of the category of possessiveness as a binary opposition. According to the semantics of the name of the possessor, his person, animacy, the degree of his concreteness or abstractness, and the semantics of the object of possession, many linguists distinguish such oppositions as alienable/unalienable appurtenance, internal/external possession, temporary/permanent possessiveness, absolute/relative appurtenance, actual/virtual possession, legal/somatic appurtenance. In the context of the gradual opposition possessive relations can be represented in the form of absolute/rela- 
tive appurtenance, inalienable appurtenance, relatively inalienable possession, occasionally inalienable and properly alienable appurtenance. According to another interpretation, the object can be inalienable, semi-alienable and alienable. Onomasiological approach proponents describe the possessiveness using as a basis the extra linguistic reality: they describe eventual types of possessors, potential types of objects of possession, try to anticipate their potential relationship. Semasiological approach supporters take as a basis specific language and speech facts - various possessive constructions. They analyze the influence of the form of possessive constructions (presence/absence of noun determiners, verbs) on its semantics.

Key words: opposition, unalienable possession, alienable possession, internal possession, external possession, temporary possession, permanent possession, actual possession, virtual possession, onomasiological approach, semasiological approach.

\section{References}

1. Balli Sh. Obshchaya lingvistika i voprosy frantsuzskogo yazyka. Per. s 3-go fr. izd. E. V. i T. V. Venttsel'. Red., vstup. st. i primech. R. A. Budagova. 2-e izd., ster. [General linguistics and problems of French. Translation from the 3rd French edition by E. V. and T. V. Ventsel'; editing, introductory article and note by R.A. Budagova. 2nd edition, stereotypical]. Moscow, Editorial URSS Publ., 2001. 416p. (in Russian).

2. Bally Ch. L'expression des idées de sphère personnelle et de solidarité dans les langues indo-européennes. Festschrift Louis Gauchat, Paris, 1926.

3. Zhurinskaya M. A. Imennye posessivnye konstruktsii i problema neottorzhimoy prinadlezhnosti [Nominative possessive constructions and the problem of unalienable possession]. Kategorii bytiya i obladaniya $v$ yazyke [Categories of being and possession in language]. Moscow, Nauka Publ., 1977. Pp. 194-258 (in Russian).

4. Guillaume G. Le problème de l'article et sa solution dans la langue française. Paris, Hachette et c-ie, 1919. 318 p.

5. Pottier B. Théorie et analyse en linguistique. Paris, Hachette, 1987. 224 p.

6. Lentsa A. L. Shirokoznachnost' glagola i kontekst [Broadness of the verb and context]. Kishinev, Shtiintsa Publ., 1987. 98 p. (in Russian).

7. lliya L. I. Ocherki po grammatike sovremennogo frantsuzskogo yazyka [Modern French grammar studies]. Moscow, Vysshaya shkola Publ., 1970. 176 p. (in Russian).

8. Liperovskiy V. P. Posessivnye konstruktsii v indoariyskikh yazykakh (khindi, urdu, pandzhabi, bengal'skiy) [Possessive constructions in Indo-Aryan languages (Hindi, Urdu, Punjabi, Bengali]. Moscow, Institute of Oriental Studies RAS Publ., 2002. 163 p. (in Russian).

9. Tseytlin S. N. Semanticheskaya kategoriia posessivnosti v russkom yazyke i eye osvoeniye rebenkom [The notional category of possessiveness in Russian and its assimilation by children]. Semanticheskiye kategorii v detskoy rechi [Notional categories in child speech]. Saint-Petersburg, NestorIstoriya Publ., 2007. Pp. 201-219 (in Russian).

10. Butinov N. A., Likhtenberg Yu. M. Yazyki narodov Melanezii [Melanesian people languages]. Narody Avstralii i Okeanii. Pod redaktsiey S. A. Tokareva, S. P. Tolstova [Australia and Oceania people. Edited by S. A. Tokarev, S. P. Tolstov]. Moscow, Academy of Sciences USSR Publ., 1956. Pp. 375-392 (in Russian).

11. Golovacheva A. V. Kategoriya posessivnosti v plane soderzhaniya [Category of possessiveness in terms of content]. Kategoriya posessivnosti v slavyanskikh i balkanskikh yazykakh [Possessiveness category in Slavic and Balkan languages]. Moscow, Nauka Publ., 1989. Pp. 44-111 (in Russian).

12. Tulina T. A. Funktsional'naya tipologiya slovosochetaniy [Functional typology of word-combinations]. Kiev, Vishcha shkola Publ., 1976.176 p. (in Russian).

13. Layonz D. Vvedeniye v teoreticheskuyu lingvistiku [Introduction in theoretical linguistics]. Moscow, URSS Publ., 2010. 541 p. (in Russian).

Davletshina S. M., Bashkir State Pedagogical University (ul. Oktyabr'skoy revolyutsii, 3a, Ufa, Republic of Bashkortostan, Russian Federation, 450000). E-mail: davletshinasm@mail.ru 